\title{
Different Effect of IgA Nephropathy and Polycystic Kidney Disease on Arterial Stiffness
}

\author{
István Késői ${ }^{a, c}$ Balázs Sági ${ }^{a}$ Orsolya I. Tóth ${ }^{a}$ Tibor Vas $^{a}$ Attila Fazekas $^{a}$ \\ Tibor Kovács $^{a}$ Tünde Pintér ${ }^{b}$ István Wittmann ${ }^{a} \quad$ Judit Nagy ${ }^{a}$ \\ ${ }^{a}$ Nephrology Center and 2nd Department of Internal Medicine and beart Center, Medical Faculty, \\ University of Pécs, Pécs, and ' Komló Health Center, Department of Internal Medicine, Komló, Hungary
}

\section{Key Words}

Arterial stiffness $\cdot$ Chronic kidney disease $\cdot \lg \mathrm{A}$

nephropathy $\cdot$ Polycystic kidney disease $\cdot$ Renal function

\begin{abstract}
Background: Renal function is a major predictor of vascular function and cardiovascular diseases. Little information exists about the effect of specific renal diseases on vascular function in chronic kidney diseases (CKD). Methods: One hundred and twenty patients (60 with IgA nephropathy, IgAN, and 60 with polycystic kidney disease, PKD) with CKD stages 1-4 were studied and compared. Pulse-wave velocity was measured by the digital volume pulse (DVP) method and stiffness index ( $\mathrm{SI}_{\mathrm{DVP}}$ ) was derived. Results: All CKD (IgAN and PKD) patients had increased $S_{\text {DVP }}$ compared to controls (10.39 vs. $8.87 \pm 1.79 \mathrm{~m} / \mathrm{s}, \mathrm{p}=0.008$ ). PKD patients had increased $\mathrm{Sl}_{\mathrm{DVP}}$ compared to IgAN and controls $(11.14 \pm 2.19$, $9.66 \pm 2.02$ and $8.87 \pm 1.79 \mathrm{~m} / \mathrm{s}$, respectively, $\mathrm{p}<0.001)$. An inverse correlation was found between $\mathrm{Sl}_{\mathrm{DVP}}$ and glomerular filtration rate in all CKD (IgAN and PKD) patients $(p=0.001)$ and in IgAN alone $(p<0.01)$, but not in PKD. With multivariate regression analysis, only age and 24 -hour systolic blood pressure exerted independent effects on SIDVP. Conclusions: Compared to controls, arterial stiffness was increased in CKD
\end{abstract}

patients. However, arterial stiffening was more pronounced in PKD than in IgAN, suggesting that vascular function is not similarly altered in etiologically different CKD groups. The fact that blood pressure was an independent risk factor underscores a therapeutic opportunity.

Copyright $\odot 2011$ S. Karger AG, Basel

\section{Introduction}

Patients with chronic kidney disease (CKD) often die of cardiovascular (CV) disease before even requiring renal replacement therapy $[1,2]$. Although we know that any degree of decreased renal function or any proteinuria increases the risk for $\mathrm{CV}$ disease, the mechanisms linking $\mathrm{CKD}$ and $\mathrm{CV}$ diseases are not fully explained and likely involve both traditional and nontraditional CV risk factors. We focused our attention on damaged vascular function as one of the nontraditional mechanisms responsible for the disproportionate CV disease burden in CKD patients. Noninvasive assessment of vascular function with a well-documented bearing on CV mortality risk is now available by the determination of arterial stiffness [3].

Along with atherosclerosis (mainly affecting the intima of the arteries), arteriosclerosis (affecting mainly the

\section{KARGER}

Fax +41613061234 E-Mail karger@karger.ch www.karger.com
(C) 2011 S. Karger AG, Basel

$1420-4096 / 11 / 0343-0158 \$ 38.00 / 0$

Accessible online at:

www.karger.com/kbr
Prof. Dr. Judit Nagy

Second Department of Medicine and Nephrological Center

University of Pécs, Pacsirta u. 1

HU-7624 Pécs (Hungary)

Tel. +36 72536 074, E-Mail judit.nagy@ aok.pte.hu 
media of large and middle-sized arteries) is the most important arterial disease also in CKD patients. Arteriosclerosis characterized by reduced arterial elasticity or compliance is closely related to arterial stiffness. Longitudinal epidemiologic studies have demonstrated the independent predictive value of arterial stiffness on CV outcome in different populations [4-7]. It is generally accepted that arterial stiffness is increased in patients with end-stage renal disease (ESRD) [8-13]. Novel data suggest pronounced arterial stiffening in CKD patients with microalbuminuria or mild-to-moderately decreased renal function [14-17]. The mechanisms of increased arterial stiffening in CKD patients are not entirely defined, but may include chronic volume overload, chronic microinflammation, lipid peroxidation, abnormalities of the nitric oxide system, sympathetic overactivity, activation of the renin-angiotensin-aldosterone system (RAAS), increased mechanical stress by hypertension, and calcification of the arterial wall $[18,19]$.

The population of CKD patients in the stiffness studies was not homogenous according to the etiology of the renal disease. No comprehensive study has yet been conducted in patients with uniform types of CKD. Therefore, we wanted to examine and compare the arterial stiffness in two homogenous forms of CKD with different etiology: in immune-mediated IgA nephropathy (IgAN) and in inherited polycystic kidney disease (PKD). It was supposed that the arterial stiffness is increased in both CKD groups but on the basis of the different pathogenesis of the two renal diseases (immune-mediated vs. inherited) arterial stiffening is not equally altered in the two CKD populations.

IgAN is the most common immunologically mediated glomerular renal disease in the world [20]. Longer observation in many countries has shown that IgAN commonly causes ESRD in as many as $40 \%$ of patients within 20 years after diagnosis [21-23]. For this reason, the disease is very suitable for longitudinal CV disease and CV risk assessment of blood pressure, lipid value, and glucose metabolic disorders. For instance, Finnish IgAN patients were shown to develop much more premature $\mathrm{CV}$ disease than the general Finnish population [23].

$\mathrm{PKD}$ is the most common inherited renal disease and occurs in 1 of 400-1,000 individuals [24]. In most of the cases, it shows an autosomal-dominant inheritance. Two genes (polycystin genes 1 and 2) are implicated in its development. The clinical picture is characterized by cystic involvement of the kidneys with slow progression to ESRD and by some extrarenal CV manifestations, e.g. intra- and extracranial aneurysms, cardiac valvular de- fect and increased carotid intima-media thickness [25, 26]. It is accepted that CV complications are the main cause of death also in PKD $[27,28]$.

We studied cohorts of well-characterized IgAN and PKD patients matched for age, kidney function, the most important $\mathrm{CV}$ risk factors and treatments, and focused our attention on their vascular function (arterial stiffness). Our purpose was 2-fold. We wanted to identify the effect of kidney diseases per se on arterial stiffness of these nonuremic patients clarifying whether the two homogenous forms of kidney diseases with different etiology have the same effect on arterial stiffness or not. Furthermore, we wanted to identify the CV risk factors with the strongest determinants on arterial stiffness in our CKD patients.

\section{Patients and Methods}

A cross-sectional study was performed in 120 CKD patients (60 IgAN and 60 PKD patients) with normal or mild-to-moderately decreased renal function (CKD stage 1-4). All of the CKD patients were followed up in the Outpatient Department of the Nephrological Center, University of Pécs, Hungary. The diagnosis was verified by renal biopsy in IgAN patients, and was based on typical abdominal ultrasound picture in PKD. Patients with confounding acute disorders including infections, unstable coronary heart disease, uncontrolled diabetes, or not yet adequately controlled high blood pressure (BP $>180 / 110 \mathrm{~mm} \mathrm{Hg}$ ) were excluded from the study. Patients with supraventricular arrhythmias were also excluded. The patients were advised to consume a low-sodium- (maximum $5 \mathrm{~g}$ sodium chloride/day) and protein-restricted diet (0.6-0.8 g/kg ideal body weight/day) depending on their renal function [29]. The internal review board approved the study and written informed consent was obtained.

\section{Risk Factor Assessment}

The classic CV risk factors were analyzed in all groups. The patients underwent a 75-gram glucose tolerance test. Impaired glucose tolerance (IGT) was defined as a 2-hour glucose level between 7.8 and $11.1 \mathrm{mmol} / \mathrm{l}$. If it was above $11.1 \mathrm{mmol} / \mathrm{l}$, diabetes mellitus (DM) was diagnosed. Impaired fasting glucose was established if the fasting glucose value was between 6.1 and 6.9 $\mathrm{mmol} / \mathrm{l}$ and the 2-hour glucose level was less than $7.8 \mathrm{mmol} / \mathrm{l}$ [30]. If any of them was detected, glucose metabolic disorder was diagnosed. Dyslipidemia was defined as a triglyceride level $>1.7$ $\mathrm{mmol} / \mathrm{l}$ or high-density cholesterol (HDL) $<1.0 \mathrm{mmol} / \mathrm{l}$ for men or $<1.3 \mathrm{mmol} / \mathrm{l}$ for women. Twenty-four-hour ambulatory blood pressure monitoring (ABPM) was performed in every patient (ABPM-IV, Meditech, Hungary). Twenty-four-hour systolic and diastolic blood pressure, pulse pressure, diurnal index and heart rate were evaluated. Patients were termed hypertensive if their 24hour average blood pressure on ABPM exceeded 130/80 mm Hg, or if they required antihypertensive treatment. Glomerular filtration rate was estimated (eGFR) according to the Cockroft-Gault formula adjusted for body surface $\left(\mathrm{ml} / \mathrm{min} / 1.73 \mathrm{~m}^{2}\right)$. The degree 
Fig. 1. The Pulse Trace system. A finger clip containing an infrared light-emitting diode and a receiver is applied to the index finger of the dominant hand (adapted from the users' manual of Micro Medical Co., Rochester, UK). The curve on the left side is derived from the volume change of the digital artery. DVP comprises two distinct waves within one cardiac cycle. The time between the first peak and the inflection point in the waveforms is determined. $\mathrm{SI}_{\mathrm{DVP}}$ can be calculated by the following equation: $\operatorname{SI}_{\mathrm{DVP}}(\mathrm{m} / \mathrm{s})=$ body height $/ \Delta \mathrm{t}_{\mathrm{DVP}}$.

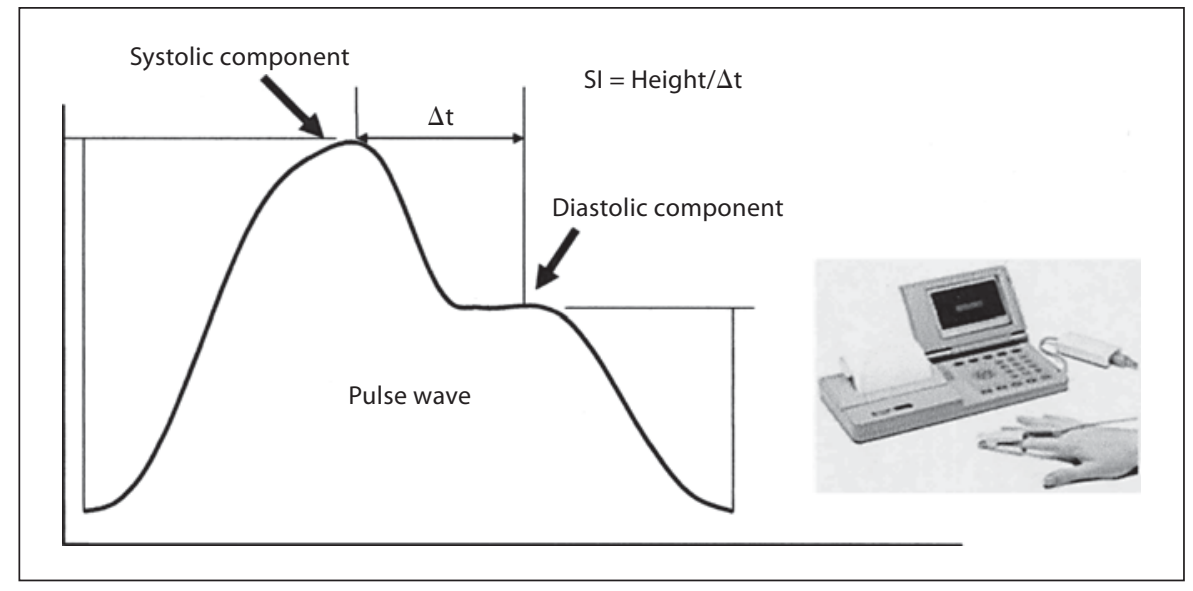

of renal insufficiency of the patients was classified according to the Clinical Practice Guidelines for Chronic Kidney Diseases from the National Kidney Foundation - Kidney Disease Outcomes Quality Initiative Group for CKD [31] as follows: CKD 1-2 group (eGFR $\geq 60 \mathrm{ml} / \mathrm{min}$ ), CKD 3-4 group (eGFR: $15-59 \mathrm{ml} /$ min). Patients with ESRD (CKD5, eGFR $<15 \mathrm{ml} / \mathrm{min}$ ) or those receiving renal replacement therapy were not included in this study.

Fifty subjects with normal renal function and with no history of renal disease formed the control group. These persons had variable elements of CV risk factors. They exhibited a similar age range as the patients and were recruited from amongst the general community. Their data including the parameters of ABPM were analyzed similarly to IgAN and PKD patients.

\section{Vascular Stiffness Determinations}

Finger photoplethysmographic method with the Pulse Trace system, Micro Medical Ltd., Rochester, UK) was used for the estimation of pulse-wave velocity (PWV) [32, 33]. The method enables to determine the stiffness index (SI) which can be derived from the digital volume pulse (DVP) and is reflected as $\mathrm{SI}_{\mathrm{DVP}}$ [34]. A finger clip containing an infrared light-emitting diode and a receiver was applied to the index finger of the dominant hand to get the DVP (fig. 1). The DVP comprises two distinct waves within one cardiac cycle, i.e. an early systolic peak arising from pressure wave propagating from the heart along the arterial tree to the finger followed by a delayed second peak caused by pressure wave reflected backward mainly from the aortic bifurcation. The time between the first peak and the inflection point in the waveforms was determined $\left(\Delta \mathrm{t}_{\mathrm{DVP}}\right)$. $\mathrm{SI}_{\mathrm{DVP}}$ was calculated by the following equation: $\mathrm{SI}_{\mathrm{DVP}}(\mathrm{m} / \mathrm{s})=$ body height $/ \Delta \mathrm{t}_{\mathrm{DVP}}$ [35]. Because the timing of the diastolic component relative to the systolic component depends on the PWV of pressure waves in the aorta and large arteries, the increased $\mathrm{SI}_{\mathrm{DVP}}$ mirrors the propagation of the arterial stiffening $[36,37]$. More details of the validity of the method can be seen in the Discussion section.

Patients and controls had taken their regular medicines as necessary. The participants were asked not to smoke and not to drink coffee on the day of the examination. All subjects were examined in the supine position after at least 10 min rest. A single waveform was obtained by averaging DVP contours during a period of $30 \mathrm{~s}$.
To enhance the accuracy of the investigation of $\mathrm{SI}_{\mathrm{DVP}}$, five period samples were taken and the upper and lower merit of DVP was deleted. The remaining three merits were averaged and used in further analysis. A variability test was performed with the remaining three merits. All measurements were performed in the morning hours between 9 and 11 a.m., thereby eliminating confounding effects of circadian variability. The person analyzing the data was not aware of any clinical information regarding the subjects.

\section{Statistical Analysis}

All results are presented as mean value \pm SD for variables with normal distribution, unless otherwise indicated. The difference between the clinical parameters of IgAN, PKD and the control groups was investigated by one-way ANOVA. Pearson $\chi^{2}$ or Fisher's exact test were applied to analyze categorical variables. Correlation analyses were performed to determine association between renal function as well as blood pressure and $\mathrm{SI}_{\mathrm{DV} \text {. }}$ Multinomial logit was used to assess the difference between the CKD and control groups during ageing. Univariate and multivariate linear regression analyses were performed to identify independent risk factors associates with SI $_{\text {DVP. }}$. Nine risk factors were analyzed: age, gender, 24-hour systolic blood pressure, 24-hour diastolic blood pressure, glucose metabolic disorders (DM, IGT and IFG), dyslipidemia, BMI, hyperuricemia and eGFR. $p<0.05$ was considered statistically significant. Data analysis was performed using the SPSS software program version 13.0 (SPSS Inc., Chicago, Ill., USA).

\section{Results}

\section{Clinical and Demographic Characteristics of CKD Patients and Controls}

Clinical and demographic population variables are summarized in table 1 . The incidence of classic CV risk factors (hypertension, glucose metabolic disorders, dyslipidaemia, obesity, age, smoking habit) was similar across the different groups, including systolic, diastolic, 
Table 1. Baseline characteristics of the patients

\begin{tabular}{|c|c|c|c|c|}
\hline & $\begin{array}{l}\text { PKD group } \\
(\mathrm{n}=60)\end{array}$ & $\begin{array}{l}\text { IgAN group } \\
(\mathrm{n}=60)\end{array}$ & $\begin{array}{l}\text { Control group } \\
(\mathrm{n}=50)\end{array}$ & $\mathrm{p}$ \\
\hline Male, $\mathrm{n}(\%)^{*}$ & $21(35)$ & $36(60)$ & $30(60)$ & $<0.05$ \\
\hline Age, years & $45 \pm 11$ & $46 \pm 13$ & $45 \pm 13$ & NS \\
\hline Hypertension, n (\%) & $49(82)$ & $49(82)$ & $31(62)$ & NS \\
\hline Systolic BP, $\mathrm{mm} \mathrm{Hg}^{\mathrm{a}}$ & $131 \pm 18$ & $126 \pm 15$ & $127 \pm 14$ & NS \\
\hline Diastolic BP, $\mathrm{mm} \mathrm{Hg}^{\mathrm{a}}$ & $80 \pm 10$ & $76 \pm 8$ & $76 \pm 10$ & NS \\
\hline Pulse pressure, $\mathrm{mm} \mathrm{Hg}^{\mathrm{a}}$ & $51 \pm 11$ & $50 \pm 12$ & $51 \pm 9$ & NS \\
\hline Heart rate, beats $/ \mathrm{min}^{\mathrm{a}}$ & $74 \pm 10$ & $76 \pm 11$ & $73 \pm 6$ & NS \\
\hline Obesity, n (\%) & $23(38)$ & $19(32)$ & $19(38)$ & NS \\
\hline Obesity BMI & $28.0 \pm 6.2$ & $27.4 \pm 5.1$ & $27.9 \pm 5.1$ & NS \\
\hline Dyslipidemia, n (\%) & $27(45)$ & $30(50)$ & $27(54)$ & NS \\
\hline Glucose metabolic disorders, n (\%) & $13(22)$ & $19(32)$ & $17(34)$ & NS \\
\hline Current smokers, n (\%) & $22(37)$ & $17(28)$ & $14(28)$ & NS \\
\hline $\mathrm{eGFR}, \mathrm{ml} / \mathrm{min}^{* *}$ & $70 \pm 37$ & $72 \pm 35$ & $108 \pm 19$ & $<0.05$ \\
\hline \multicolumn{5}{|l|}{ Treatment } \\
\hline ACEI/ARB, n (\%) & $46(77)$ & $50(83)$ & $31(62)$ & NS \\
\hline Calcium antagonists, $\mathrm{n}(\%)^{*}$ & $31(52)$ & $12(20)$ & $18(36)$ & $<0.05$ \\
\hline$\beta$-Blockers, n (\%) & $21(35)$ & $16(27)$ & $19(38)$ & NS \\
\hline$\alpha$-Receptor blockers, n (\%) & $5(8)$ & $3(5)$ & $3(6)$ & NS \\
\hline Imidazolin receptor agonist, $\mathrm{n}(\%)$ & $2(3)$ & $2(3)$ & $3(6)$ & NS \\
\hline Diuretics, $\mathrm{n}(\%)$ & $7(12)$ & $5(8)$ & $5(10)$ & NS \\
\hline Statins, n (\%) & $22(37)$ & $21(35)$ & $23(46)$ & NS \\
\hline
\end{tabular}

${ }^{\mathrm{a}}$ At ABPM. ${ }^{*} \mathrm{p}<0.05$ PKD group vs. IgAN and control groups, ${ }^{* *} \mathrm{p}<0.05 \mathrm{PKD}$ group and IgAN group vs. control group. NS = Nonsignificant.

and pulse pressure measured by 24-hour ABPM. There was a gender difference, because the PKD group contained significantly more female patients. Most of the patients were receiving antihypertensive drugs. The use of calcium antagonists was more frequent in the PKD group, but the other antihypertensive and lipid-lowering therapy (angiotensin-converting enzyme inhibitors, ACEI, angiotensin-II receptor blockers, ARB, $\beta$-blockers, $\alpha$-receptor blockers, imidazolin receptor agonists, diuretics and statins) was similar in the two CKD groups. The eGFR of the control group was normal, but the eGFR of the PKD and IgAN groups was significantly lower than in controls. The eGFR of the two CKD groups was statistically similar (table 1).

A variability testing was performed with the three $\mathrm{SI}_{\mathrm{DVP}}$ merits, as outlined earlier. The result of this analysis was $0.52 \pm 0.63 \mathrm{~m} / \mathrm{s}$, indicating quite low variability of our data.

\section{Comparison of $S I_{D V P}$ in CKD Patients and Controls}

$\mathrm{SI}_{\mathrm{DVP}}$ was increased in the group of all CKD (IgAN and PKD) patients compared to controls (10.39 vs. $8.87 \pm 1.79$ $\mathrm{m} / \mathrm{s}, \mathrm{p}=0.008)$. Separately examining the two CKD groups, the $\mathrm{SI}_{\mathrm{DVP}}$ of the $\mathrm{PKD}$ group $(11.14 \pm 2.19 \mathrm{~m} / \mathrm{s})$ was significantly higher than the SI $\mathrm{DVP}_{\mathrm{P}}$ of the $\operatorname{IgAN}(9.66 \pm$ $2.02 \mathrm{~m} / \mathrm{s})$ and control groups $(8.87 \pm 1.79 \mathrm{~m} / \mathrm{s})(\mathrm{p}<0.001$ in both relations) while there was no significant difference in the $\mathrm{SI}_{\mathrm{DVP}}$ values between the IgAN group and the controls (fig. 2a). Because of the gender difference between the PKD and IgAN groups, to exclude its effect on arterial stiffness, the $\mathrm{SI}_{\mathrm{DVP}}$ of men and women was analyzed separately in both groups. No significant difference was found in $\mathrm{SI}_{\mathrm{DVP}}$ either among PKD patients ( $\mathrm{SI}_{\mathrm{DVP}}$ of men: $11.19 \pm 1.88 \mathrm{~m} / \mathrm{s}$ vs. $\mathrm{SI}_{\mathrm{DVP}}$ of women: $11.11 \pm 2.36 \mathrm{~m} / \mathrm{s}, \mathrm{p}$ was nonsignificant) or among IgAN patients $\left(\mathrm{SI}_{\mathrm{DVP}}\right.$ of men: $9.57 \pm 2.16 \mathrm{~m} / \mathrm{s}$ vs. SI $_{\text {DVP }}$ of women: $9.80 \pm 1.85 \mathrm{~m} / \mathrm{s}$, $\mathrm{p}$ was nonsignificant) on the basis of gender.

\section{$S I_{D V P}$ and Renal Function in CKD Patients}

The two groups of CKD patients were matched according to their eGFR. There were 24 patients in CKD stage 3-4 and 36 patients in CKD stage 1-2 both in the IgAN and the PKD groups. The SI $I_{D V P}$ of the CKD 3-4 IgAN patients was significantly higher than that of the controls 


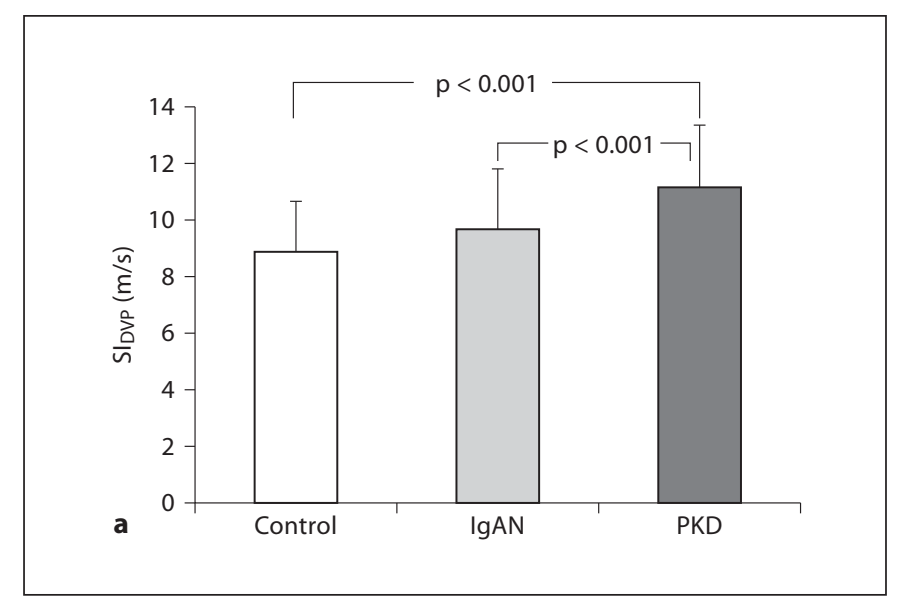

Fig. 2. a $S I_{D V P}$ in the CKD groups. $S I_{D V P}$ of the $P K D$ group was significantly higher than $\mathrm{SI}_{\mathrm{DVP}}$ of IgAN patients and controls: $11.14 \pm 2.19,9.66 \pm 2.02$ and $8.87 \pm 1.79 \mathrm{~m} / \mathrm{s}$, respectively $(\mathrm{p}<$ 0.001 in both relations). There was no significant difference in $\mathrm{SI}_{\mathrm{DVP}}$ values between the IgAN group and controls. b $\mathrm{SI}_{\mathrm{DVP}}$ in the IgAN subgroups (CKD 3-4, CKD 1-2) and in controls. $\mathrm{SI}_{\mathrm{DVP}}$ of CKD 3-4 IgAN patients was significantly higher than of controls $(10.43 \pm 2.30$ vs. $8.87 \pm 1.79 \mathrm{~m} / \mathrm{s}, \mathrm{p}<0.05)$ while $\mathrm{SI}_{\mathrm{DVP}}$ of CKD 1-2 IgAN patients $(9.15 \pm 1.72 \mathrm{~m} / \mathrm{s})$ did not differ significantly from controls. Arterial stiffness of the CKD 3-4 patients was slightly, but not significantly higher than of CKD 1-2 patients in IgAN. c SI $I_{\text {DVP }}$ in the PKD subgroups (CKD 3-4, CKD $1-2$ ) and in controls. The $\mathrm{SI}_{\mathrm{DVP}}$ in both groups (CKD 3-4 and of CKD 1-2 patients) was significantly higher than in controls (11.41 \pm 2.23 and $10.95 \pm 2.17 \mathrm{~m} / \mathrm{s}$ vs. $8.87 \pm 1.79 \mathrm{~m} / \mathrm{s}, \mathrm{p}<0.001$, respectively).

$(10.43 \pm 2.30$ vs. $8.87 \pm 1.79 \mathrm{~m} / \mathrm{s}, \mathrm{p}<0.05)$, while the $\mathrm{SI}_{\text {DVP }}$ of CKD 1-2 IgAN patients $(9.15 \pm 1.72 \mathrm{~m} / \mathrm{s})$ was not significantly different from the controls (fig. 2b). There was no significant difference in stiffening of the CKD 3-4 patients compared to the CKD 1-2 patients in the IgAN group. In the PKD patients, the $\mathrm{SI}_{\mathrm{DVP}}$ in both groups (CKD 3-4 and of CKD 1-2 patients) was significantly higher than in controls $(11.41 \pm 2.23$ and $10.95 \pm 2.17$ $\mathrm{m} / \mathrm{s}$ vs. $8.87 \pm 1.79 \mathrm{~m} / \mathrm{s}, \mathrm{p}<0.001$, respectively (fig. $2 \mathrm{c}$ ). There was a significant negative correlation between $\mathrm{SI}_{\mathrm{DVP}}$ and eGFR in the group comprising all (IgAN and PKD) CKD patients $(\mathrm{r}=-0.288, \mathrm{p}=0.001)$ (fig. $3 \mathrm{a})$ and in the IgAN patients $(r=-368, p<0.01$, fig $3 b)$, but not in the PKD patients ( $r=-0.229$, p was nonsignificant; fig $3 c)$.

\section{Assessment of Risk Factors}

Univariate linear regression analyses were performed in both renal groups to assess the confounding factors affecting $\mathrm{SI}_{\mathrm{DVP}}$ : age, gender, 24-hour systolic blood pres-
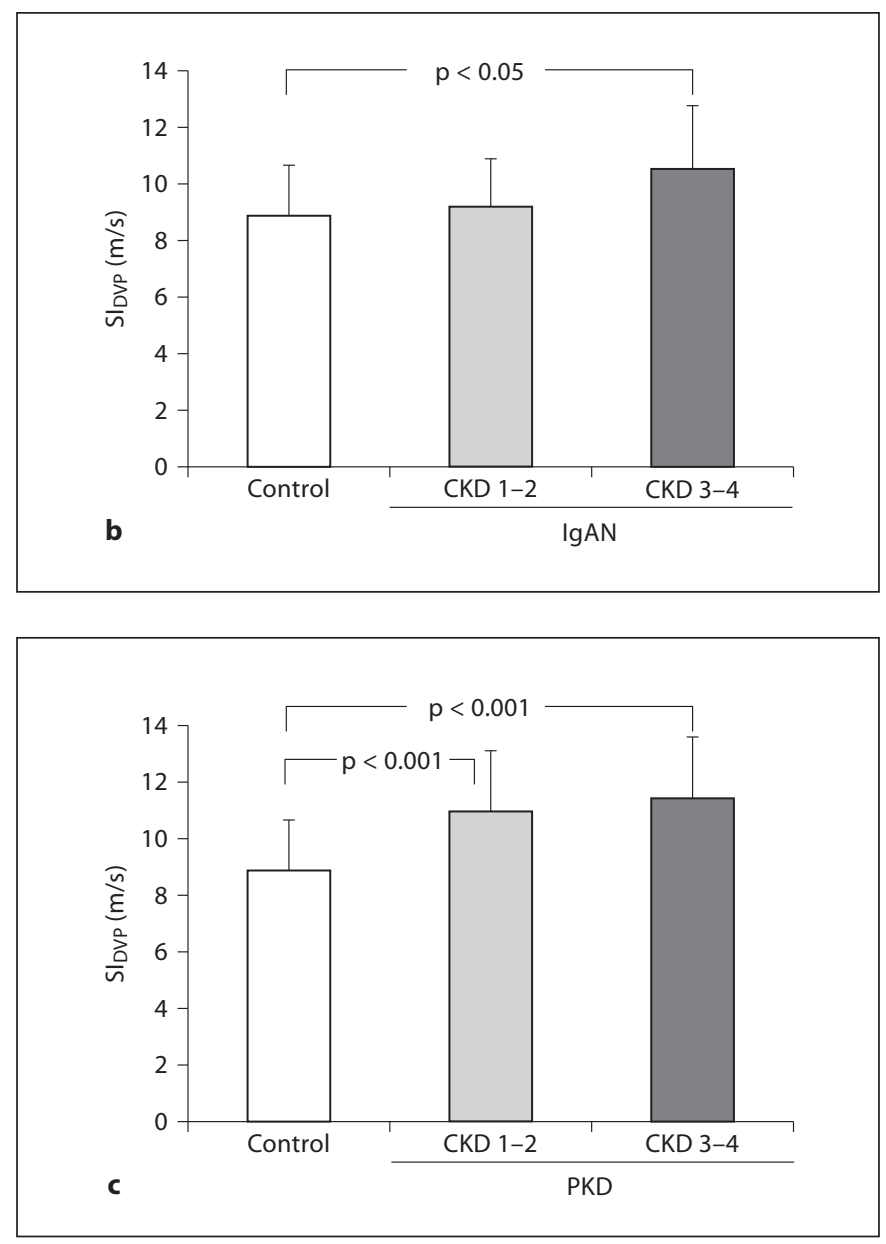

sure, 24-hour diastolic blood pressure, glucose metabolic disorders (diabetes, IGT or IFG), dyslipidemia, BMI, hyperuricemia, and eGFR. In this model, age, 24-hour systolic blood pressure and 24-hour diastolic blood pressure as well as eGFR had a significant impact on $\mathrm{SI}_{\mathrm{DVP}}$ when analyzing all renal patients together (IgAN and PKD). With multivariate regression analysis, examining all renal patients' age and 24-hour systolic blood pressure together exerted independent effects on $\mathrm{SI}_{\mathrm{DV} P}$. Furthermore, there was a significant correlation between $\mathrm{SI}_{\mathrm{DVP}}$ and 24-hour systolic blood pressure as well as 24-hour diastolic blood pressure in the group of all CKD (IgAN and PKD) patients $(\mathrm{r}=0.252, \mathrm{p}=0.02$ and $\mathrm{r}=0.301, \mathrm{p}=$ 0.007 , respectively).

\section{Age Dependency of $S I_{D V P}$}

Using an estimated regression model to compare the increase of $\mathrm{SI}_{\mathrm{DVP}}$ during aging in the three groups, it was demonstrated that the $\mathrm{SI}_{\mathrm{DVP}}$ of PKD and IgAN patients 

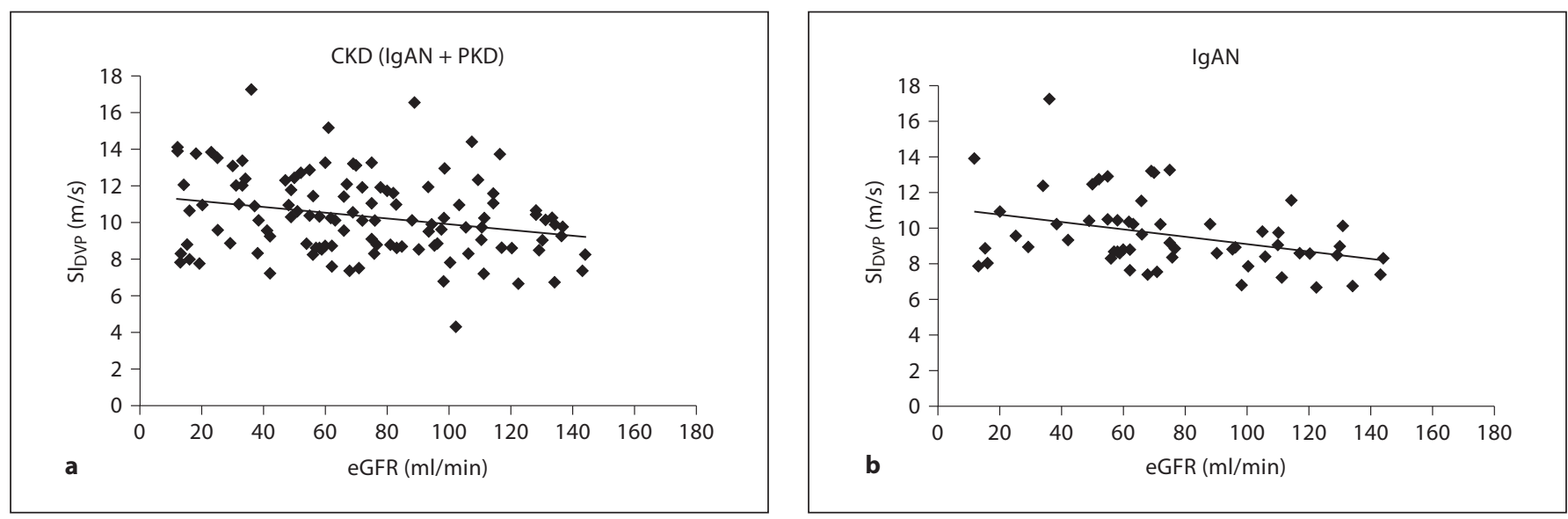

Fig. 3. a Correlation between eGFR and $\mathrm{SI}_{\mathrm{DVP}}$ in all CKD patients. There was a significant correlation between eGFR and $\mathrm{SI}_{\mathrm{DVP}}$ : $y=-0.0178 x+11.663 ; r=-0.288, p=0.001$. $\mathbf{b}$ Correlation between

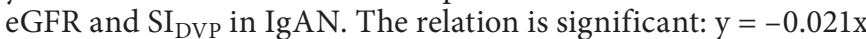
$+11.179 ; \mathrm{r}=-0.368, \mathrm{p}<0.01$. c Correlation between eGFR and $\mathrm{SI}_{\mathrm{DVP}}$ in PKD. There was no significant correlation between eGFR and arterial stiffness in this group: $y=-0.0162 x+12.355$; $\mathrm{r}=-0.229, \mathrm{p}$ was nonsignificant.

increased significantly faster than the $\mathrm{SI}_{\mathrm{DVP}}$ of controls in all the age groups (PKD vs. controls $0.091-0.073>0$, beta $0.814,95 \%$ CI 1.682-3.028, $\mathrm{p}<0.001$; IgAN vs. controls $0.089-0.073>0$, beta $0.313,95 \%$ CI $1.059-1.764, \mathrm{p}<$ 0.005) (fig. 4).

\section{Discussion}

The novel findings of this study are that in two homogenous CKD populations (IgAN and $\mathrm{PKD}$ ) a rather marked but not similar increase of arterial stiffness exists as compared to controls. Arterial stiffness $\left(\mathrm{SI}_{\mathrm{DVP}}\right)$ was significantly higher in $\mathrm{PKD}$ patients than in IgAN as well as in controls. Furthermore, an inverse significant correlation was found between $\mathrm{SI}_{\mathrm{DVP}}$ and eGFR in the group of all CKD (IgAN and PKD) patients, as well as in IgAN patients but not in PKD. There was a significant correlation between $\mathrm{SI}_{\mathrm{DVP}}$ and systolic and diastolic blood pressure in the group of all CKD (IgAN and PKD) patients.

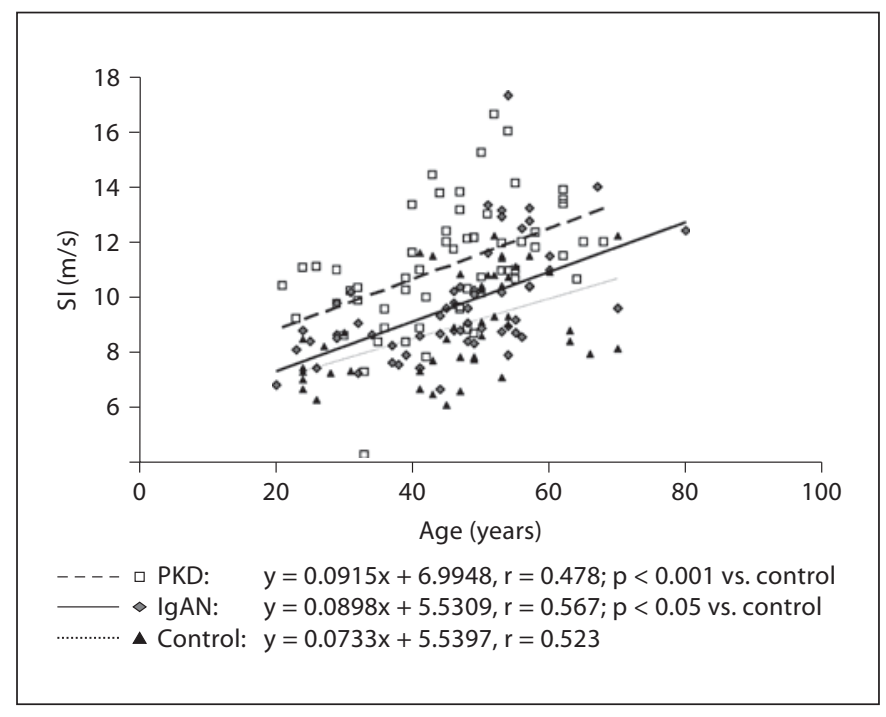

Fig. 4. Estimated regression model. The three lines representing the three examined groups demonstrate that the $\mathrm{SI}_{\mathrm{DVP}}$ of the CKD patients was increased in both groups $(\mathrm{PKD}>\operatorname{IgA})$ and in all age groups compared to controls. 
The fact that blood pressure was also an independent risk factor underscores a more aggressive therapeutic opportunity.

Previous studies have reported increased stiffness in renal patients with ESRD before or during renal replacement therapy $[6,9]$. However, in most studies dealing with CKD patients, the etiology of the CKD is rarely mentioned and stiffness of renal patients with different etiology have not been compared yet. Furthermore, there are only a few publications on arterial stiffening in renal patients with preserved or only slightly reduced renal function. Our purpose was the routine, pre-symptomatic screening of IgAN and PKD patients to obtain the arterial stiffness. We aimed to find those CKD patients who have an increased risk of developing further CV disease. We selected patients with relatively preserved glomerular function to specifically minimize the influence of uremia-related factors such as volume overload, disorders of calcium and phosphate metabolism, and other confounders on arterial stiffness.

We identified an increased vascular stiffness in both CKD groups (IgA and PKD) compared to controls. SI $\mathrm{DVP}_{\mathrm{P}}$ of IgAN patients was significantly lower than $\mathrm{SI}_{\mathrm{DVP}}$ of PKD patients. Looking for the connection between $\mathrm{SI}_{\mathrm{DVP}}$ and renal function there was a stepwise (but not significant) increase of arterial stiffness corresponding to the stages of the CKD and a significant correlation between arterial stiffness and the degree of impairment of renal function (eGFR) in the IgAN patients. Wang et al. [38] reported similar findings in $102 \mathrm{CKD}$ patients with various renal diseases from Taiwan. They found that SI was independently associated with renal function, a finding we could not corroborate here. However, the patients described by Wang et al. [38] may have been different. Ethnic and environmental (for instance dietary) differences could be responsible, as well as methodology. The increase of arterial stiffness associated with the parallel decline of renal function in smaller groups of etiologically non-homogenous CKD patients from France, UK and the Netherlands [39-41]. These patients generally had more advanced renal disease than those reported here.

At the same time, vascular stiffness of PKD patients was significantly increased in the early stages (CKD 1-2) of the disease (fig. 2c) and in already juvenile patients (fig. 4). The stiffness did not correlate with the degree of renal function. Our finding confirms the results of Borresen et al. [42] who found that pulse-wave reflection was amplified even in young PKD patients with normal renal function. As Ecder and Schrier [25] summarized recently, $\mathrm{CV}$ abnormalities are common in PKD. Cardiac diastol- ic dysfunction, endothelial dysfunction, increased intima-media thickness, impaired coronary flow velocity reserve and cardiac valvular abnormalities may present in young patients with PKD who have well-preserved renal function. The etiology of early CV abnormality in PKD is not clear. Polycystins 1 and 2 are strongly expressed in the endothelium as well as in human adult vascular smooth cells and the vascular abnormalities in PKD patients may be related to altered expressions of polycystin with primary disruption of polycystin functions [43]. Further observations demonstrated an early exaggerated activation of the RAAS both in adults and in children with PKD even before the onset of hypertension [44-47]. A possible explanation can be cyst expansion causing a local renal ischemia [24]. Immunohistochemical studies of nephrectomy specimens from PKD patients have shown hyperplasia of renin-secreting cells of the juxtaglomerular apparatus, suggesting that chronic stimulation of the RAAS is present [48].

Some investigators suggest that the RAAS is very important in the development of arterial stiffness not only in PKD patients [49]. ACEI or ARB treatment significantly improved the parameters of stiffness in the general population, hypertensive patients and renal patients on dialysis, as reviewed by Gusbeth-Tatomir [50]. Hypertension is also very common in IgAN and PKD [51]. However, there are no data about the stiffness-decreasing effect of ACEI and/or ARB treatment in IgAN and PKD patients. The beneficial impact of RAAS inhibition may be limited to some but not all CKD patients, since most of our patients received ACEI and/or ARB therapy. Possibly, our treatment was begun too late or was not aggressive enough or should have been combined with renin inhibition or mineralocorticoid receptor blockade.

Arterial stiffness can be measured by several methods. Aortic pulse wave velocity (PWV) is the indirect measurement of large arterial stiffness most often used. SI ${ }_{D V P}$ derived by the contour analysis of DVP is an alternative simple method to analyze arterial stiffness. However, as Sollinger et al. [9] discussed, the two methods do not provide identical information. Aortic PWV, measured over the carotid-femoral region, determines the velocity of pressure transmission between both detection sites and is related inversely to aortal compliance. $\mathrm{SI}_{\mathrm{DVP}}$ is a composite parameter influenced by flexibility of the large central arteries as well as reflective properties of the peripheral arterial bed. In addition to the velocity of pressure wave reflection along the large central conduit arteries, the DVP waveform is affected by characteristics of ventricular ejection and the exact distribution of aortic and more 
peripheral sites of pressure wave reflection [52]. Despite these differences, a significant correlation was found between $\mathrm{SI}_{\mathrm{DVP}}$ and PWV in healthy individuals, patients with ESRD and patients with coronary artery disease [34, $47,53]$. The usefulness of the $\mathrm{SI}_{\mathrm{DVP}}$ as a noninvasive alternative to detect arterial stiffness was also successfully tested in patients with hypertension, diabetes mellitus and children $[36,54,55]$. Furthermore, $\mathrm{SI}_{\mathrm{DVP}}$ can help in the risk stratification of both hypertensive and apparently healthy people with different CV risk factors $[56,57]$.

The technique of finger photoplethysmography has the advantages of being relatively simple, easily portable and also avoids some difficulties during the detection of pressure waveform encountered with other methods. Such confounders include the accurate recording of femoral pressure waveforms in patients with obesity and severe atherosclerosis or the psychological discomfort of the inguinal location $[58,59]$.

\section{Limitations}

We are aware of limitations in our study. Because of the cross-sectional design, we cannot say for certain that the association between increased arterial stiffness and decreased renal function is causal in our CKD patients. Since the course of both diseases exceeds often more than
20-30 years, the authors will not be in a position to answer longitudinal questions. Not all of the patients had 24-hour creatinine clearance values determined and, for this reason, we used the estimated renal function (Cockroft-Gault formula) for mathematical analysis. Finally, we examined a relatively small number of patients to get well-matched homogenous renal populations.

In conclusion, the present study suggests that various types of kidney diseases may act differently on arterial stiffness. Studies investigating the arterial stiffness in CKD patients should take this possibility into consideration. Further longitudinal well-conducted clinical investigations are warranted to clear the impact of reduced arterial elasticity on the progression of different renal diseases. Future longitudinal research studies should focus on the better understanding of the complex interplay between arterial function, CV risk factors and treatments, $\mathrm{CV}$ diseases and CKD.

\section{Acknowledgement}

This study was supported by research grants from the Hungarian Society of Nephrology and from the Hungarian Society of Hypertension.

\section{References}

1 Foley RN, Parfrey PS, Sarnak MJ: Clinical epidemiology of cardiovascular disease in chronic renal disease. Am J Kidney Dis 1998; 32:S112-S119.

-2 Levin A: Cardiac disease in chronic kidney disease: current understandings and opportunities for change. Blood Purif 2004;22:2127.

- 3 Laurent S, Cockroft J, Van Bortel L, Boutouyrie P, Giannattasio C, Hayoz D, Pannier B,Viachopoulos C, Wilkinson I, StruijkerBoudier H, European Network for Non-invasive Investigation of Large Arteries: Expert consensus document on arterial stiffness: methodological issues and clinical applications. Eur Heart J 2006;27:2588-2605.

4 Laurent S, Boutouyrie, P, Asmar R, Gautier I, Laloux B: Cardiovascular mortality in hypertensive patients. Hypertension 2001;37: 1236-1241.

5 Laurent S, Katsahian S, Fassot C, Tropeano AI, Gautier I, Laloux B, Boutouyrie P: Aortic stiffness is an independent predictor of fatal stroke in essential hypertension. Stroke 2003;34:1203-1206.

-6 Cruickshank K, Riste L, Anderson SG, Wright JS, Dunn G, Gosling RG: Aortic pulse-wave velocity and its relationship to mortality in diabetes and glucose intolerance: an integrated index of vascular function? Circulation 2002;106:2085-2090

7 Willum-Hansen T, Staessen JA, Torp-Pedersen C, Rasmussen S, Thijs L, Ibsen H, Jeppesen J: Prognostic value of aortic pulse wave velocity as index of arterial stiffness in the general population. Circulation 2006;113: 664-670.

8 London GM, Guerin AP, Marchais SJ, Metivier F, Pannier B, Adda H: Arterial media calcification in end stage renal disease: impact on all-cause and cardiovascular mortality. Nephrol Dial Transplant 2003;18:1731-1740.

-9 London GM, Marchais SJ, Guérin AP, Métivier F: Arteriosclerosis, vascular calcifications and cardiovascular disease in uraemia. Curr Opin Nephrol Hypertens 2005; 14:525531.

10 Guerin AP, Blacher J, Pannier B, Marchais SJ, Safar ME, London GM: Impact of aortic stiffness attenuation on survival of patients in end-stage renal failure. Circulation 2001; 103:987-992.

11 Sollinger D, Mohaupt MG, Wilhelm A, Uehlinger D, Frey FJ, Eisenberger U: Arterial stiffness assessed by digital volume pulse correlates with comorbidity in patients with ESRD. Am J Kidney Dis 2006;48:456-463.

$\checkmark 12$ Covic A, Gusbeth-Tatomir P, Goldsmith DJA: Arterial stiffness in renal patients: an update. Am J Kidney Dis 2005;45:965-977.

13 El Hadj Othmane T, Nemcsik J, Fekete BCs, Deák Gy, Egresits J, Fodor E, Logan AG, Németh ZsK, Járai Z, Szabó T, Szathmári M, Kiss I, Tislér A: Arterial stiffness in hemodialysis: which parameter to measure to predict cardiovascular mortality? Kidney Blood Press Res 2009;32:250-257.

- 14 Upadhyay A, Hwang SJ, Mitchell GF, Vasan RS, Vita JA, Stantchev PI, Meigs JB, Larson MG, Levy D, Benjamin EJ, Fox CS: Arterial stiffness in mild-to-moderate CKD. J Am Soc Nephrol 2009;20:2044-2053.

$>_{15}$ Briet M, Bozec E, Laurent S, Fassot C, London GM, Jacquot C, Froissart M, Houillier P, Boutouyrie P: Arterial stiffness and enlargement in mild-to moderate chronic kidney disease. Kidney Int 2006;69:350-357.

16 Wang MC, Tsai WC, Chen JY, Huang JJ: Stepwise increase in arterial stiffness corresponding with the stages of chronic kidney disease. Am J Kidney Dis 2005;45:494-501. 
-17 Townsend RR, Wimmer NJ, Chirinos JA, Parsa A, Weir M, Perumal K, Lash JP, Chen J, Steigerwalt SP, Flack J, Go AS, Rafey M, Rahman M, Sheridan A, Gadegbeku CA, Robinson NA, Joffe M: Aortic PWV in chronic kidney disease: a CIRC ancillary study. Am J Hypertens 2010;23:282-289.

- 18 London GM, Marchais SJ, Guerin AP, Pannier B: Arterial stiffness: pathophysiology and clinical impact. Clin Exp Hypertens 2004;26:689-699.

19 Gusbeth-Tatomir P, Covic A: Causes and consequences of increased arterial stiffness in chronic kidney disease patients. Kidney Blood Press Res 2007;30:97-107.

20 D'Amico G: The commonest glomerulonephritis in the world: IgA nephropathy. Q J Med 1987;64:709-727.

-21 Floege J, Freehally J: IgA nephropathy: recent developments. J Am Soc Nephrol 2000; 11:2395-2403.

22 Syrjänen J, Mustonen J, Pasternack A: Hypertrigliceridaemia and hyperuricaemia are risk factors for progression of IgA nephropathy. Nephrol Dial Transplant 2000;15:34-42.

23 Myllymäki J, Syrjänen J, Helin H, Pasternack A, Kattainen A, Mustonen J: Vascular diseases and their risk factors in IgA nephropathy. Nephrol Dial Transplant 2006;21:18761882.

24 Torres WE, Harris PC, Pirson Y: Autosomal dominant polycystic kidney disease. Lancet 2007;369:1287-1301.

-25 Ecder T, Schrier RW: Cardiovascular abnormalities in autosomal-dominant polycystic kidney disease. Nat Rev Nephrol 2009;5:221228.

-26 Kocaman O, Oflaz H, Yeleker E, Dursun M, Erdogan D, Demirel S, Alisir S, Turgut F, Mercanoglu F, Ecder T: Endothelial dysfunction and increased carotid intima-media thickness in patients with autosomal dominant polycystic kidney disease. Am J Kidney Dis 2004;43:854-860.

27 Fick GM, Johnson AM, Hammond WS, Gabow PA: Causes of death in autosomal polycystic kidney disease. J Am Soc Nephrol 1995;5:2046-2056.

-28 Perrone RD, Ruthazer R, Terrin NC: Survival after end-stage renal disease in autosomal dominant polycystic kidney disease: contribution of extrarenal complications to mortality. Am J Kidney Dis 2001;38:777-784.

29 Haddad N, Brown C, Hebert LA: Retarding progression of kidney disease; in Feehally J, Floege J, Johnson RJ (eds): Comprehensive Clinical Nephrology. Amsterdam, Mosby, Elsevier, 2007, pp 823-830.

-30 The Task Force on Diabetes and Cardiovascular Diseases of the European Society of Cardiology (ESC) and of the European Association for the Study of Diabetes (EASD): Guidelines on diabetes, pre-diabetes, and cardiovascular diseases: executive summary. Eur Heart J 2007;28:88-136.

-31 National Kidney Foundation: K/DOQI clinical practice guidelines for chronic kidney disease: evaluation, classification and stratification. Am J Kidney Dis 2002;39:S1S266.

32 Millasseau SC, Ritter JM, Takazawa K, Chowienczyk PJ: Contour analysis of the photopletysmographic pulse measured at the finger. Review. J Hypertens 2006;24:1449-1456.

33 Alty SR, Angarita-Jaimes N, Millasseau SC, Chowienczyk PJ: Predicting arterial stiffness from the digital volume pulse waveform. IEEE Trans Biomed Eng 2007;54:2268-2275.

34 Millasseau SC, Kelly RP, Ritter JM, Chowienczyk PJ: Determination of age-related increases in large artery stiffness by digital pulse contour analysis. Clin Sci 2002;103:371-377.

35 Chowienczyk PJ, Kelly RP, MacCallum H, et al: Photopletysmographic assessment of pulse wave reflection. J Am Coll Cardiol 1999;34:2007-2014.

-36 Millasseau SC, Kelly RP, Ritter JM, Chowienczyk PJ: The vascular impact of aging and vasoactive drugs: comparison of two digital volume pulse measurements. Am J Hypertens 2003; 16:467-472.

37 Sollinger D, Mohaupt MG, Wilhelm A, Uehlinger D, Frey FJ, Eisenberger U: Arterial stiffness assessed by digital volume pulse correlates with comorbidity in patients with ESRD. Am J Kidney Dis 2006;48:456-463.

- 38 Wang MC, Tsai WC, Chen JY, Huang JJ: Stepwise increase in arterial stiffness corresponding with the stages of chronic kidney disease. Am J Kidney Dis 2005;45:494-501.

39 Briet M, Bozec E, Laurent S, Fassot C, London GM, Jacquot C, Froissart M, Houillier P, Boutouyrie P: Arterial stiffness and enlargement in mild-to moderate chronic kidney disease. Kidney Int 2006;69:350-357.

40 Lacy P, Carr SJ, O’Brien D, Fentum B, Williams B, Paul SK, Robinson TG: Reduced glomerular filtration rate in pre-dialysis nondiabetic chronic kidney disease patients is associated with impaired baroreceptor sensitivity and reduced vascular compliance. Cli Sci 2006;110:101-108.

41 Konings C, Dammers R, Rensma PL, Kooman JP, Hoeks A, Kornet L, Gladziwa U, Van der Sande F, Leunissen K: Arterial wall properties in patients with renal failure. Am J Kidney Dis 2002;39:1206-1212.

42 Borresen ML, Wang D, Strandgaard S: Pulse wave reflection is amplified in normotensive patients with autosomal-dominant polycystic kidney disease and normal renal function. Am J Nephrol 2007;27:240-246.

43 Griffin MD, Torres WE, Grande JP, Kumar R: Vascular expression of polycystins. J Am Soc Nephrol 1997;8:616-626.

44 Gabow PA, Chapman AB, Johnson AM, Tangel DJ, Duley IT, Kaehny WD, Manco-Johnson M, Schrier RW: Renal structure and hypertension in autosomal dominant polycystic kidney disease. Kidney Int 1990;38: $1177-1180$

-45 Fick GM, Duley IT, Johnson AM, Strain JD, Manco-Johnson ML, Gabow PA: The spectrum of autosomal dominant polycystic kidney disease in children. J Am Soc Nephrol 1994;4:1654-1660.
46 Harrap SB, Davies DL, Macnicol AM, Dominiczak AF, Fraser R, Wright AF, Watson ML, Briggs JD: Renal, cardiovascular and hormonal characteristics of young adults with autosomal dominant polycystic kidney disease. Kidney Int 1991;40:501-508.

47 Barrett BJ, Foley R, Morgan J, Hefferton D, Parfrey P: Differences in hormonal and renal vascular responses between normotensive patients with autosomal dominant polycystic kidney disease. Kidney Int 1994;46:11181123.

48 Graham RC, Lindop GBM: The anatomy of the renin-secreting cells in adult polycystic kidney disease. Kidney Int 1988;33:10841090.

49 Mahmud A, Feely J: Arterial stiffness and the renin-angiotensin-aldosterone system. J Renin Angiotensin Aldosterone Syst 2004;5: 102-108.

50 Gusbeth-Tatomir P, Covic A: Causes and consequences of increased arterial stiffness in chronic kidney disease patients. Kidney Blood Press Res 2007;30:97-107.

-51 Nagy J, Kovács T, Wittmann I: Renal protection in IgA nephropathy requires strict blood pressure control. Nephrol Dial Transplant 2005;20:1533-1539.

52 van der Heijden-Spek JJ, Staessen JA, Fagard RH, Hoeks AP, Boudier HA, van Bortel LM: Effect of age on brachial artery wall properties differs from the aorta and is gender dependent: a population study. Hypertension 2000;35:637-642.

53 Woodman RJ, Kingwell BA, Beilin LJ, Hamilton SE, Dart AM, Watts GF: Assessment of central and peripheral arterial stiffness. Am J Hypertens 2005;18:249-260.

-54 Simonetti GD, Eisenberger U, Bergmann IP, Frey FJ, Mohaupt MG: Pulse contour analysis: a valid assessment of central arterial stiffness in children? Pediatr Nephrol 2008;23: 439-444.

55 Hashimoto J, Watabe D, Kimura A, Takahashi $\mathrm{H}$, Ohkubo T, Totsune K, Imai Y: Determinants of the second derivate of the finger photoplethysmogram and brachial-ankle pulse-wave velocity: the Okasama Study. Am J Hypertens 2005;18:477-485.

56 Chen JY, Tsai WC, Lin CC, Huang YY, Hsu $\mathrm{CH}$, Liu PY, Chen JH: Stiffness index derived from digital volume pulse as a marker of target organ damage in untreated hypertension. Blood Press 2005;14:233-237.

57 Gunarathne A, Patel JV, Hughes EA, Lip GY: Measurement of stiffness index by digital volume pulse analysis technique: clinical utility in cardiovascular disease risk stratification. Am J Hypertens 2008;21: 866-872.

58 Mackenzie IS, Wilkinson IB, Cockroft JR: Assessment of arterial stiffness in clinical practice. Q J Med 2002;95:67-74.

59 Padilla JM, Berjano EJ, Sáiz J, Fácila L, Díaz P, Mercé S: Assessment of relationship between blood pressure, pulse wave velocity and digital volume pulse. Comput Cardiol 2006;33:893-896. 